\title{
Rotational Barrier and Quantification of Electron- Donating Substituent Effects: a Computational Study of para-Substituted Benzaldehydes
}

\author{
Ali Hussain Yateem
}

\author{
Department of Chemistry, College of Science, University of Bahrain, P. O. Box 32038, Sakhir, Kingdom of Bahrain \\ Author's e-mail address: alihali222@gmail.com
}

RECEIVED: August 7, 2020 * REVISED: September 10, 2020 * ACCEPTED: September 18, 2020

Abstract: The rotational barrier around the phenyl-formyl bond between the minimum and transition states of para-substituted benzaldehydes was computationally studied for 34 electron-donating substituents. The rotational barrier exhibited very good correlation with shortening of the phenyl-formyl bond, lengthening of carbonyl bond, increase of electron density at the formyl group, increase of stabilization energy, lowering of chemical shift in the ${ }^{13} \mathrm{C}$ NMR of the formyl carbon, and with the values of empirical Hammett $\sigma_{p}{ }^{+}$constants. Therefore, rotational barrier is a useful quantum mechanical parameter for quantifying the electron-donating substituent effect and $\pi$-conjugation in parasubstituted benzaldehydes. Based upon the rotational barrier a scale has been set in this work to judge the electron donating effect of substituents. Moreover, a canonical structure has been proposed for stronger electron-donating substituents. The results of this study reveal that simultaneous presence of electron acceptor formyl group and electron-donating groups is mandatory for the extension of resonance stabilization.

Keywords: Rotational barrier, substituent effects, electron-donating groups, para-substituted benzaldehydes.

\section{INTRODUCTION}

S UBSTITUENT effects in aromatic compounds find extensive practical applications in the conductivity of molecular electronic devices, molecular photoresponsive switches, super-resolution fluorescence microscopy, light harvesting dye-sensitized solar cell, and organic electroluminescent devices. ${ }^{[1-7]}$ Hammett constants are the most widely used parameters to measure the electronic effect of substituents in substituted aromatic compounds. ${ }^{[8,9]}$ Several quantum mechanical methods such as substituent effect stabilization energy, ${ }^{[10]}$ charge of substituent active region, ${ }^{[10,11]}$ energy dispersive analysis, ${ }^{[12]}$ and molecular electrostatic potential[13] used to describe substituent effect in aromatic system show good correlation with original or modified Hammett constants.

The rotational barrier (RB) has been reported to increase with the enhancement of electronic delocalization due to electron donor or accepting groups in parasubstituted anilines, ${ }^{[14]}$ phenols, ${ }^{[15]}$ benzaldehydes, ${ }^{[16,17]}$ acetophenones, ${ }^{[16,18]}$ benzyl cations, anions, and radicals ${ }^{[19]}$ and disubstituted 1,3-butadienes. ${ }^{[20]}$ However, with the exception of electron-withdrawing effects in para-substituted anilines, ${ }^{[14]}$ these studies are limited to small number of substituents. Moreover, no quantitative correlation has been documented in these studies between the effect of substituent on rotational barrier and conjugation. Thus, there is an urgent need to quantify the electron-donating substituent effects of a large number of substituents and to ensure such effects by correlating with a maximum number of empirical and quantum mechanical parameters.

This work uses internal rotational barrier as a quantum mechanical approach to quantify the electron-donating substituent effects in 36 para-substituted benzaldehydes. The carbonyl group is sensitive to electronic variations at different sites in aromatic molecules and it is able to enter into conjugation with adjacent $\pi$ systems. In addition, further insights in the $\pi$-electron delocalization process can be gained because several parameters within the formyl group can be correlated with the rotational barrier. 
Other parameters such as Hammett constants, IR frequencies, and chemical shifts of ${ }^{1} \mathrm{H}$ and ${ }^{13} \mathrm{C}$ nuclei can also be related to rotational data. The rotational barrier of the formyl group depends on the $\pi$-electron delocalization from the aromatic ring to the polarized carbonyl group and this barrier is expected to be modified by aromatic substitution, especially at para-position. The current work offers details of the correlation of the rotational barrier with geometric, atomic, molecular, and spectroscopic parameters, as well as with the empirical Hammett $\sigma_{\mathrm{p}}{ }^{+}$constants.

\section{Method}

The gas-phase barrier to internal rotation around the phenyl-formyl single bond in a series of parasubstituted benzaldehydes was measured. The internal rotational potential energy curves were obtained by performing geometry optimization calculations at a set of $\mathrm{H}-\mathrm{C} 1-\mathrm{C} 2-\mathrm{C} 3$ dihedral angles (Scheme 1) ranging from 0 to $180^{\circ}$ with an increment of $10^{\circ}$. Increment was decreased to $1^{\circ}$ and then to $0.1^{\circ}$ when calculations were performed for the structures close to the transition state. The RB here is the barrier between the minimum state (the most stable structure) at a dihedral angle of $0^{\circ}$ or very close to $0^{\circ}$ and the transition state at a dihedral angle between $89.0^{\circ}$ and $191.0^{\circ}$. All the independent structural parameters were optimized except dihedral angle. The minimum (negative) electrostatic potential $E S_{\text {min }}$ was evaluated from QSAR model only if it was on carbonyl oxygen of both minimum and transition states. As a result, electrostatic potential was not calculated for anionic substituents.

The stabilization energy was calculated using the relationships shown in [Eq. (1)]. ${ }^{[10,21]}$

$$
\begin{aligned}
& \text { Stabilization energy }=E\left(\mathrm{C}_{6} \mathrm{H}_{5}-\mathrm{X}\right)+ \\
& +E\left(\mathrm{C}_{6} \mathrm{H}_{5}-\mathrm{CHO}\right)-E\left(\mathrm{X}-\mathrm{C}_{6} \mathrm{H}_{4}-\mathrm{CHO}\right)-E\left(\mathrm{C}_{6} \mathrm{H}_{6}\right)
\end{aligned}
$$

where $X$ is the substituent. Large value of stabilization energy means greater stabilization relative to the parent benzene due to the substituent effect.

The approach here is to plot changes in structural, atomic, molecular, and spectroscopic properties between the minimum and transition states against rotational barrier. Computational calculations were carried out at the

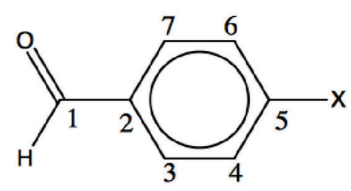

Scheme 1. Numbering of the atoms in para-substituted benzaldehydes. $\mathrm{X}$ represents an electrondonating substituent. density functional $\omega B$ 97X-D level ${ }^{[22]}$ with $6-31 G^{* *}$ basis set using Spartan'14 (v. 1.1.4), ${ }^{[23]}$ except for ${ }^{1} \mathrm{H}$ and ${ }^{13} \mathrm{C}$ NMR chemical shifts of formyl proton and carbon where energy density functional EDF2/6-31G* level[24] was used. Models other than EDF2/6-31G* in Spartan'14 are not accurately corrected for chemical shifts and they show inconsistency in the relative positions of NMR peaks. The approach using $\omega B 97 X-D / 6-31 G^{* *}$ was used in the current work as it is a preferred computational model for such studies on parasubstituted anilines ${ }^{[14]}$ and disubstituted 1,3-butadienes. ${ }^{[20]}$

Energies of the minimum and transition states in both theoretical methods were corrected for zero-point energies from the measurement of IR vibrational frequencies except in calculation of stabilization energy where they almost cancel out in [Eq. (1)]. The character of structures of the minimum and transition states was confirmed by vibrational frequency analysis. The structure of the transition state for all molecules has only one imaginary frequency whereas the structure corresponding to the minimum state has no imaginary frequency. The empirical Hammett $\sigma_{\mathrm{p}}{ }^{+}$constants were taken from literature. ${ }^{[25,26]}$

Substituents considered here cover a range of weakly to strongly electron-donating groups owing to their negative $\sigma_{\mathrm{p}}{ }^{+}$values. In addition, data for two strong electron-withdrawing substituents, $\mathrm{CN}$ and $\mathrm{NO}_{2}$, were included for the purpose of comparing with the trends of the electron-donating substituents. In case of more than one conformer per molecule, the conformer with the lowest energy was chosen after performing conformers distribution analysis.

\section{RESULTS AND DISCUSSION}

\section{Substituent Effect on Geometrical, Atomic, Molecular, and Spectroscopic Properties of para-Substituted Benzaldehydes}

Tables 1 and 2 show values of RB, phenyl-formyl bond length $r(\mathrm{C} 1-\mathrm{C} 2)$, carbonyl bond length $r(\mathrm{C} 1=0)$, carbonyl stretching frequencies $\mathrm{v}_{\mathrm{C} 1=0}$, natural atomic charge on carbonyl carbon $Q_{n}(C 1)$, natural atomic charge on carbonyl oxygen $Q_{n}(O)$, and minimum electrostatic potential $E S_{\text {min, }}$, for respective minimum and transition states of 36 parasubstituted benzaldehydes. The substituents were arranged in order of decreasing rotational barrier between the minimum and transition states.

The C1-C2 single bond distances for almost all minimum states of para-substituted benzaldehydes are smaller than that of benzaldehyde (1.481 $\AA$ ) being the shortest for $\mathrm{O}^{-}$substituent (1.434 $\AA$ ). The $\mathrm{C} 1-\mathrm{C} 2$ bond distances in transition states are longer than those in 
minimum states but their values are close to each other except for the anionic substituents as listed in Table 2. In contrast to $\mathrm{C} 1-\mathrm{C} 2$ bond distances, the $\mathrm{C} 1=\mathrm{O}$ double bond distances are showing opposite trend in both minimum and transition states although the changes are smaller. The stretching frequency of carbonyl group decreases with the increase in RB in minimum states but in transition states the decrease in frequency is only with substituents of very large

Table 1. Calculated parameters for minimum (equilibrium) states of para-substituted benzaldehydes.

\begin{tabular}{|c|c|c|c|c|c|c|c|}
\hline Substituent X & $\mathrm{RB} / \mathrm{kcal} \mathrm{mol}^{-1}$ & $R(\mathrm{C} 1-\mathrm{C} 2) / \AA$ & $R(\mathrm{C} 1=\mathrm{O}) / \AA$ & $v_{\mathrm{C} 1=0} / \mathrm{cm}^{-1}$ & $Q_{n}(C 1) / e$ & $Q_{n}(O) / e$ & $E S_{\min } / \mathrm{kJ} \mathrm{mol}^{-1}$ \\
\hline $\mathrm{O}^{-}$ & 19.28 & 1.434 & 1.231 & 1779 & 0.360 & -0.649 & \\
\hline $\mathrm{OCH}_{2} \mathrm{O}^{-}$ & 17.76 & 1.439 & 1.228 & 1785 & 0.369 & -0.635 & \\
\hline $\mathrm{S}^{-}$ & 15.08 & 1.447 & 1.225 & 1794 & 0.377 & -0.616 & \\
\hline $\mathrm{NNO}_{2}^{-}$ & 13.92 & 1.451 & 1.222 & 1804 & 0.384 & -0.604 & \\
\hline $\mathrm{O}\left(\mathrm{CH}_{2}\right)_{2} \mathrm{O}^{-}$ & 12.65 & 1.458 & 1.220 & 1812 & 0.393 & -0.595 & \\
\hline $\mathrm{OPO}_{3} \mathrm{H}^{-}$ & 12.01 & 1.460 & 1.218 & 1822 & 0.394 & -0.583 & \\
\hline $\mathrm{CH}_{2} \mathrm{CO}_{2}^{-}$ & 11.69 & 1.463 & 1.218 & 1822 & 0.397 & -0.582 & \\
\hline $\mathrm{NHCH}_{3}$ & 11.12 & 1.469 & 1.214 & 1837 & 0.396 & -0.555 & -201.76 \\
\hline $\mathrm{N}\left(\mathrm{C}_{2} \mathrm{H}_{5}\right)_{2}$ & 11.04 & 1.467 & 1.214 & 1836 & 0.395 & -0.557 & -205.58 \\
\hline $\mathrm{CO}_{2}^{-}$ & 10.87 & 1.465 & 1.217 & 1825 & 0.399 & -0.579 & \\
\hline $\mathrm{NH}_{2}$ & 10.62 & 1.470 & 1.213 & 1840 & 0.397 & -0.552 & -197.11 \\
\hline $\mathrm{N}\left(\mathrm{CH}_{3}\right)_{2}$ & 10.52 & 1.468 & 1.214 & 1838 & 0.396 & -0.555 & -203.83 \\
\hline $\mathrm{O}\left(\mathrm{CH}_{2}\right)_{2} \mathrm{CH}_{3}$ & 10.15 & 1.474 & 1.212 & 1845 & 0.399 & -0.545 & -188.10 \\
\hline $\mathrm{OH}$ & 9.98 & 1.474 & 1.212 & 1846 & 0.400 & -0.545 & -182.35 \\
\hline $\mathrm{OCH}_{3}$ & 9.87 & 1.474 & 1.212 & 1844 & 0.400 & -0.545 & -185.19 \\
\hline $\mathrm{OCH}_{2} \mathrm{CH}_{3}$ & 9.78 & 1.474 & 1.212 & 1844 & 0.400 & -0.546 & -186.69 \\
\hline $\mathrm{OC}_{6} \mathrm{H}_{5}$ & 9.68 & 1.475 & 1.212 & 1847 & 0.400 & -0.543 & -183.16 \\
\hline $\mathrm{OCH}\left(\mathrm{CH}_{3}\right)_{2}$ & 9.63 & 1.473 & 1.212 & 1845 & 0.399 & -0.546 & -189.40 \\
\hline $\mathrm{N}=\mathrm{NN}\left(\mathrm{CH}_{3}\right)_{2}$ & 9.44 & 1.476 & 1.212 & 1845 & 0.400 & -0.543 & -191.89 \\
\hline $\mathrm{F}$ & 9.21 & 1.479 & 1.212 & 1852 & 0.402 & -0.535 & -167.77 \\
\hline SH & 9.20 & 1.478 & 1.211 & 1849 & 0.401 & -0.536 & -171.39 \\
\hline $\mathrm{SCH}_{3}$ & 9.20 & 1.477 & 1.212 & 1846 & 0.400 & -0.539 & -176.70 \\
\hline 2-furyl & 9.10 & 1.478 & 1.211 & 1848 & 0.400 & -0.537 & -177.75 \\
\hline $\mathrm{CH}_{2} \mathrm{CH}_{3}$ & 9.08 & 1.479 & 1.211 & 1849 & 0.402 & -0.538 & -179.38 \\
\hline $\mathrm{C}_{5} \mathrm{H}_{10}$ & 9.05 & 1.478 & 1.211 & 1849 & 0.402 & -0.538 & -180.93 \\
\hline $\mathrm{CH}_{3}$ & 9.01 & 1.479 & 1.211 & 1850 & 0.402 & -0.538 & -179.79 \\
\hline$\left(\mathrm{CH}_{2}\right)_{2} \mathrm{CH}_{3}$ & 8.99 & 1.479 & 1.211 & 1850 & 0.402 & -0.538 & -179.15 \\
\hline $\mathrm{CH}\left(\mathrm{CH}_{3}\right)_{2}$ & 8.97 & 1.479 & 1.211 & 1849 & 0.402 & -0.538 & -179.74 \\
\hline $\mathrm{C}\left(\mathrm{CH}_{3}\right)_{3}$ & 8.94 & 1.478 & 1.211 & 1850 & 0.402 & -0.538 & -180.75 \\
\hline $\mathrm{C}_{6} \mathrm{H}_{5}$ & 8.83 & 1.479 & 1.211 & 1851 & 0.402 & -0.535 & -175.85 \\
\hline $\mathrm{CH}=\mathrm{CH}_{2}$ & 8.82 & 1.479 & 1.211 & 1849 & 0.401 & -0.535 & -174.81 \\
\hline $\mathrm{CH}_{2} \mathrm{OH}$ & 8.74 & 1.480 & 1.211 & 1851 & 0.402 & -0.536 & -172.46 \\
\hline $\mathrm{SiH}\left(\mathrm{CH}_{3}\right)_{2}$ & 8.63 & 1.481 & 1.211 & 1851 & 0.403 & -0.533 & -174.06 \\
\hline $\mathrm{H}$ & 8.58 & 1.481 & 1.210 & 1852 & 0.403 & -0.534 & -173.10 \\
\hline $\mathrm{CN}$ & 8.07 & 1.486 & 1.209 & 1857 & 0.402 & -0.520 & \\
\hline $\mathrm{NO}_{2}$ & 7.87 & 1.487 & 1.208 & 1859 & 0.402 & -0.517 & \\
\hline
\end{tabular}


RB as evident from the observation of data shown in Table 2. The largest decrease in $v_{\mathrm{C} 1=0}$ stretching frequency in minimum states is $73 \mathrm{~cm}^{-1}$ as compared to $38 \mathrm{~cm}^{-1}$ in transition states, both with $\mathrm{O}^{-}$substituent. The decrease in the $\mathrm{C} 1-\mathrm{C} 2$ bond distance indicates an increase in its double bond character, while the increase of the $\mathrm{C} 1=\mathrm{O}$ bond length and the decrease in carbonyl stretching frequencies indicate a decrease in $\mathrm{C} 1=\mathrm{O}$ double bond character.

Table 2. Calculated parameters for transition states of para-substituted benzaldehydes.

\begin{tabular}{|c|c|c|c|c|c|c|c|}
\hline Substituent X & $\mathrm{RB} / \mathrm{kcal} \mathrm{mol}^{-1}$ & $R(\mathrm{C} 1-\mathrm{C} 2) / \AA$ & $R(\mathrm{C} 1=\mathrm{O}) / \AA$ & $v_{\mathrm{C} 1=0} / \mathrm{cm}^{-1}$ & $Q_{n}(C 1) / e$ & $Q_{n}(O) / e$ & $E S_{\min } / \mathrm{kJ} \mathrm{mol}^{-1}$ \\
\hline $\mathrm{O}^{-}$ & 19.28 & 1.484 & 1.215 & 1829 & 0.438 & -0.563 & \\
\hline $\mathrm{OCH}_{2} \mathrm{O}^{-}$ & 17.76 & 1.487 & 1.214 & 1837 & 0.437 & -0.555 & \\
\hline $\mathrm{S}^{-}$ & 15.08 & 1.489 & 1.213 & 1843 & 0.434 & -0.548 & \\
\hline $\mathrm{NNO}_{2}^{-}$ & 13.92 & 1.491 & 1.212 & 1848 & 0.432 & -0.543 & \\
\hline $\mathrm{O}\left(\mathrm{CH}_{2}\right)_{2} \mathrm{O}^{-}$ & 12.65 & 1.493 & 1.212 & 1850 & 0.431 & -0.541 & \\
\hline $\mathrm{OPO}_{3} \mathrm{H}^{-}$ & 12.01 & 1.494 & 1.211 & 1854 & 0.428 & -0.534 & \\
\hline $\mathrm{CH}_{2} \mathrm{CO}_{2}^{-}$ & 11.69 & 1.494 & 1.210 & 1855 & 0.429 & -0.534 & \\
\hline $\mathrm{NHCH}_{3}$ & 11.12 & 1.500 & 1.208 & 1862 & 0.417 & -0.510 & -185.73 \\
\hline $\mathrm{N}\left(\mathrm{C}_{2} \mathrm{H}_{5}\right)_{2}$ & 11.04 & 1.499 & 1.208 & 1861 & 0.418 & -0.512 & -188.34 \\
\hline $\mathrm{CO}_{2}^{-}$ & 10.87 & 1.494 & 1.211 & 1853 & 0.430 & -0.539 & \\
\hline $\mathrm{NH}_{2}$ & 10.62 & 1.500 & 1.208 & 1863 & 0.417 & -0.509 & -183.01 \\
\hline $\mathrm{N}\left(\mathrm{CH}_{3}\right)_{2}$ & 10.52 & 1.499 & 1.208 & 1860 & 0.417 & -0.511 & -185.84 \\
\hline $\mathrm{O}\left(\mathrm{CH}_{2}\right)_{2} \mathrm{CH}_{3}$ & 10.15 & 1.501 & 1.207 & 1864 & 0.416 & -0.508 & -174.36 \\
\hline $\mathrm{OH}$ & 9.98 & 1.501 & 1.207 & 1864 & 0.415 & -0.506 & -170.47 \\
\hline $\mathrm{OCH}_{3}$ & 9.87 & 1.501 & 1.207 & 1865 & 0.416 & -0.507 & -173.08 \\
\hline $\mathrm{OCH}_{2} \mathrm{CH}_{3}$ & 9.78 & 1.501 & 1.207 & 1865 & 0.416 & -0.508 & -174.63 \\
\hline $\mathrm{OC}_{6} \mathrm{H}_{5}$ & 9.68 & 1.502 & 1.207 & 1866 & 0.415 & -0.506 & -171.55 \\
\hline $\mathrm{OCH}\left(\mathrm{CH}_{3}\right)_{2}$ & 9.63 & 1.501 & 1.207 & 1865 & 0.416 & -0.508 & -176.26 \\
\hline $\mathrm{N}=\mathrm{NN}\left(\mathrm{CH}_{3}\right)_{2}$ & 9.44 & 1.501 & 1.207 & 1864 & 0.415 & -0.508 & -181.44 \\
\hline $\mathrm{F}$ & 9.21 & 1.503 & 1.207 & 1867 & 0.413 & -0.502 & -157.00 \\
\hline $\mathrm{SH}$ & 9.20 & 1.502 & 1.207 & 1865 & 0.413 & -0.503 & -159.80 \\
\hline $\mathrm{SCH}_{3}$ & 9.20 & 1.502 & 1.207 & 1866 & 0.414 & -0.505 & -165.60 \\
\hline 2-furyl & 9.10 & 1.502 & 1.207 & 1864 & 0.414 & -0.504 & -166.75 \\
\hline $\mathrm{CH}_{2} \mathrm{CH}_{3}$ & 9.08 & 1.502 & 1.207 & 1866 & 0.415 & -0.507 & -171.12 \\
\hline $\mathrm{C}_{5} \mathrm{H}_{10}$ & 9.05 & 1.501 & 1.207 & 1865 & 0.415 & -0.507 & -171.92 \\
\hline $\mathrm{CH}_{3}$ & 9.01 & 1.502 & 1.207 & 1865 & 0.415 & -0.507 & -171.42 \\
\hline$\left(\mathrm{CH}_{2}\right)_{2} \mathrm{CH}_{3}$ & 8.99 & 1.502 & 1.207 & 1865 & 0.415 & -0.507 & -170.76 \\
\hline $\mathrm{CH}\left(\mathrm{CH}_{3}\right)_{2}$ & 8.97 & 1.502 & 1.207 & 1866 & 0.415 & -0.507 & -170.20 \\
\hline $\mathrm{C}\left(\mathrm{CH}_{3}\right)_{3}$ & 8.94 & 1.501 & 1.207 & 1864 & 0.415 & -0.507 & -171.13 \\
\hline $\mathrm{C}_{6} \mathrm{H}_{5}$ & 8.83 & 1.502 & 1.207 & 1866 & 0.414 & -0.505 & -167.02 \\
\hline $\mathrm{CH}=\mathrm{CH}_{2}$ & 8.82 & 1.502 & 1.207 & 1865 & 0.414 & -0.505 & -165.96 \\
\hline $\mathrm{CH}_{2} \mathrm{OH}$ & 8.74 & 1.502 & 1.207 & 1867 & 0.414 & -0.505 & -165.27 \\
\hline $\mathrm{SiH}\left(\mathrm{CH}_{3}\right)_{2}$ & 8.63 & 1.502 & 1.207 & 1866 & 0.414 & -0.505 & -165.77 \\
\hline $\mathrm{H}$ & 8.58 & 1.503 & 1.207 & 1867 & 0.414 & -0.505 & -166.25 \\
\hline $\mathrm{CN}$ & 8.07 & 1.505 & 1.206 & 1868 & 0.409 & -0.495 & \\
\hline $\mathrm{NO}_{2}$ & 7.87 & 1.505 & 1.205 & 1868 & 0.408 & -0.493 & \\
\hline
\end{tabular}


Table 3. Calculated rotational barrier, ${ }^{1} \mathrm{H}$ and ${ }^{13} \mathrm{C}$ NMR chemical shifts of formyl proton and carbon in minimum and transition states and differences in chemical shifts between the two states of para-substituted benzaldehydes.

\begin{tabular}{|c|c|c|c|c|c|c|c|}
\hline \multirow{2}{*}{ Substituent X } & \multirow{2}{*}{$\mathrm{RB} / \mathrm{kcal} \mathrm{mol}^{-1}$} & \multicolumn{2}{|c|}{${ }^{1} \mathrm{H}$ chemical shift / ppm } & \multirow{2}{*}{$\begin{array}{c}\Delta^{1} H \text { chemical } \\
\text { shift / ppm }\end{array}$} & \multicolumn{2}{|c|}{${ }^{13} \mathrm{C}$ chemical shift / ppm } & \multirow{2}{*}{$\begin{array}{l}\Delta^{13} \mathrm{C} \text { chemical } \\
\text { shift / ppm }\end{array}$} \\
\hline & & Min & Max & & Min & Max & \\
\hline $\mathrm{O}^{-}$ & 21.64 & 8.512 & 10.437 & 1.925 & 179.90 & 208.77 & 28.87 \\
\hline $\mathrm{OCH}_{2} \mathrm{O}^{-}$ & 19.47 & 8.668 & 10.562 & 1.894 & 182.40 & 210.51 & 28.11 \\
\hline $\mathrm{S}^{-}$ & 17.83 & 8.769 & 10.543 & 1.774 & 182.93 & 210.67 & 27.74 \\
\hline $\mathrm{NNO}_{2}^{-}$ & 15.82 & 8.920 & 10.586 & 1.666 & 185.54 & 209.33 & 23.79 \\
\hline $\mathrm{O}\left(\mathrm{CH}_{2}\right)_{2} \mathrm{O}^{-}$ & 14.10 & 9.087 & 10.523 & 1.436 & 188.40 & 209.48 & 21.08 \\
\hline $\mathrm{OPO}_{3} \mathrm{H}^{-}$ & 13.92 & 9.181 & 10.544 & 1.363 & 189.62 & 207.72 & 18.10 \\
\hline $\mathrm{CH}_{2} \mathrm{CO}_{2}^{-}$ & 13.79 & 9.113 & 10.557 & 1.444 & 188.31 & 208.09 & 19.78 \\
\hline $\mathrm{NHCH}_{3}$ & 12.49 & 9.371 & 10.578 & 1.207 & 188.17 & 204.59 & 16.43 \\
\hline $\mathrm{N}\left(\mathrm{C}_{2} \mathrm{H}_{5}\right)_{2}$ & 12.38 & 9.379 & 10.560 & 1.181 & 188.39 & 204.20 & 15.81 \\
\hline $\mathrm{CO}_{2}^{-}$ & 12.14 & 9.319 & 10.675 & 1.356 & 192.15 & 209.88 & 17.73 \\
\hline $\mathrm{NH}_{2}$ & 12.05 & 9.423 & 10.620 & 1.197 & 188.76 & 204.54 & 15.79 \\
\hline $\mathrm{N}\left(\mathrm{CH}_{3}\right)_{2}$ & 11.96 & 9.380 & 10.529 & 1.149 & 188.50 & 203.94 & 15.44 \\
\hline $\mathrm{O}\left(\mathrm{CH}_{2}\right)_{2} \mathrm{CH}_{3}$ & 11.17 & 9.493 & 10.517 & 1.024 & 189.40 & 203.10 & 13.70 \\
\hline $\mathrm{OH}$ & 11.14 & 9.516 & 10.605 & 1.089 & 189.79 & 203.77 & 13.99 \\
\hline $\mathrm{OCH}_{3}$ & 11.13 & 9.511 & 10.605 & 1.094 & 189.61 & 203.76 & 14.14 \\
\hline $\mathrm{OCH}_{2} \mathrm{CH}_{3}$ & 11.08 & 9.525 & 10.604 & 1.079 & 189.85 & 203.75 & 13.91 \\
\hline $\mathrm{OC}_{6} \mathrm{H}_{5}$ & 11.05 & 9.507 & 10.581 & 1.074 & 189.47 & 203.37 & 13.90 \\
\hline $\mathrm{OCH}\left(\mathrm{CH}_{3}\right)_{2}$ & 10.76 & 9.547 & 10.591 & 1.044 & 190.04 & 203.43 & 13.38 \\
\hline $\mathrm{N}=\mathrm{NN}\left(\mathrm{CH}_{3}\right)_{2}$ & 10.75 & 9.549 & 10.613 & 1.064 & 190.73 & 203.98 & 13.25 \\
\hline $\mathrm{F}$ & 10.67 & 9.552 & 10.561 & 1.009 & 190.48 & 202.60 & 12.12 \\
\hline SH & 10.42 & 9.532 & 10.565 & 1.033 & 190.25 & 203.51 & 13.27 \\
\hline $\mathrm{SCH}_{3}$ & 10.37 & 9.589 & 10.595 & 1.006 & 190.94 & 203.27 & 12.34 \\
\hline 2 -furyl & 10.18 & 9.608 & 10.561 & 0.953 & 190.27 & 202.10 & 11.83 \\
\hline $\mathrm{CH}_{2} \mathrm{CH}_{3}$ & 10.11 & 9.614 & 10.598 & 0.984 & 191.33 & 203.15 & 11.81 \\
\hline $\mathrm{C}_{5} \mathrm{H}_{10}$ & 10.09 & 9.629 & 10.621 & 0.992 & 191.60 & 203.66 & 12.06 \\
\hline $\mathrm{CH}_{3}$ & 9.98 & 9.621 & 10.614 & 0.993 & 191.61 & 203.46 & 11.85 \\
\hline$\left(\mathrm{CH}_{2}\right)_{2} \mathrm{CH}_{3}$ & 9.95 & 9.680 & 10.666 & 0.986 & 191.59 & 203.38 & 11.80 \\
\hline $\mathrm{CH}\left(\mathrm{CH}_{3}\right)_{2}$ & 9.91 & 9.611 & 10.596 & 0.985 & 191.57 & 203.46 & 11.88 \\
\hline $\mathrm{C}\left(\mathrm{CH}_{3}\right)_{3}$ & 9.88 & 9.622 & 10.589 & 0.967 & 191.59 & 203.43 & 11.84 \\
\hline $\mathrm{C}_{6} \mathrm{H}_{5}$ & 9.84 & 9.611 & 10.602 & 0.991 & 191.50 & 203.46 & 11.95 \\
\hline $\mathrm{CH}=\mathrm{CH}_{2}$ & 9.84 & 9.636 & 10.630 & 0.994 & 191.68 & 203.65 & 11.97 \\
\hline $\mathrm{CH}_{2} \mathrm{OH}$ & 9.82 & 9.650 & 10.605 & 0.955 & 191.73 & 203.09 & 11.37 \\
\hline $\mathrm{SiH}\left(\mathrm{CH}_{3}\right)_{2}$ & 9.67 & 9.662 & 10.596 & 0.934 & 192.67 & 203.99 & 11.32 \\
\hline $\mathrm{H}$ & 9.57 & 9.671 & 10.621 & 0.950 & 192.27 & 204.00 & 11.73 \\
\hline $\mathrm{CN}$ & 8.97 & 9.742 & 10.597 & 0.855 & 191.85 & 201.48 & 9.63 \\
\hline $\mathrm{NO}_{2}$ & 8.60 & 9.811 & 10.624 & 0.813 & 192.16 & 201.70 & 9.54 \\
\hline
\end{tabular}


It can be observed that with the increase in RB (Table 1) the natural atomic charge for the carbonyl carbon becomes less positive while the natural charge for the carbonyl oxygen becomes more negative. The minimum electrostatic potential in the vicinity of lone pairs of carbonyl oxygen also becomes more negative. Similar trends in the natural atomic charge of oxygen and electrostatic potential are observed in transition states but to a lower extent. The positive natural charge on carbonyl carbon show some increase only with a few anionic substituents in the transition states (see Table 2). The decrease in charges of carbonyl atoms and the increase in negative value of electrostatic potential indicate shift of electron density towards the formyl group.

Table 3 shows the calculated ${ }^{1} \mathrm{H}$ and ${ }^{13} \mathrm{C}$ NMR chemical shifts of formyl hydrogen and carbon of para-substituted benzaldehydes in minimum and transition states and the difference in chemical shifts between the two states for the two nuclei. All data in Table 3 are calculated using the EDF2/631G* theoretical method and the substituents are arranged in order of decreasing rotational barrier between the minimum and transition states. With the increase in RB, the ${ }^{13} \mathrm{C}$ chemical shift of formyl carbon is lowered in both the minimum and transition states, with lowering being more significant in the former states. The ${ }^{1} \mathrm{H}$ chemical shift of formyl hydrogen shows very little decrease with increasing $\mathrm{RB}$ and it can thus be considered essentially independent of RB. This upfield shift suggests greater shielding and concomitant increase in electronic density around these nuclei.

The relatively smaller change in the above mentioned parameters in transition states is because the conjugation is the lowest in these states ${ }^{[14]}$ and therefore changing substituents has a smaller effect on their values. Data of the strong electron-accepting $\mathrm{CN}$ and $\mathrm{NO}_{2}$ substituents show opposite trends in comparison to all other electron-donating substituents as shown in Tables 1-3. More notably, the $\mathrm{C} 1-\mathrm{C} 2$ bond length and carbonyl stretching frequencies $v_{\mathrm{C} 1=\mathrm{O}}$ in the molecules containing these two substituents are larger than those of benzaldehyde, and the natural charge on carbonyl oxygen is less negative compared to oxygen of benzaldehyde. Moreover, the rotational barriers around the phenyl-formyl bond in molecules containing these two groups are the lowest among the studied para-substituted benzaldehydes according to the results obtained from both computational methods.

\section{Correlation of Rotational Barrier with Substituent Effects}

Since rotational barrier is taken as the difference in energy between the minimum and transition states, so the difference in parameters of these states can be quantitatively correlated with the rotational barrier. This approach nearly cancels some small deviation in parameters that occur in

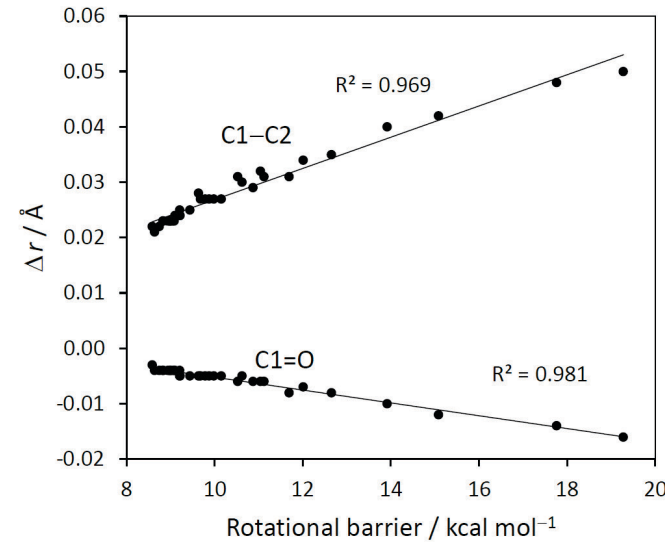

Figure 1. Plot of changes of $\mathrm{C} 1-\mathrm{C} 2$ and $\mathrm{C} 1-\mathrm{O}$ bond distances between minimum and transition states versus rotational barrier of para-substituted benzaldehydes.

both states. As a result, correlation of rotational barrier with parameters of only minimum states gives lower $R^{2}$ values. The relation between changes in different parameters between minimum and transition states and rotational barrier is shown in Tables 3 and 4, and in Figures 1-3, SI1, and $\mathrm{S} 12$. The experimental rotational barriers of benzaldehyde, $p$ $\mathrm{CH}\left(\mathrm{CH}_{3}\right)_{2}$-benzaldehyde, $p$ - $\mathrm{CH}_{3}$ benzaldehyde, $p$-F-benzaldehyde, $p$ - $\mathrm{CH}_{3} \mathrm{O}$-benzaldehyde, and $p$ - $\mathrm{N}_{(}\left(\mathrm{CH}_{3}\right)_{2}$-benzaldehyde are 7.58-7.90, 7.79-8.13, 8.15-8.20, 8.03-8.39, 9.01-9.20, and $10.73-10.8 \mathrm{kcal} \mathrm{mol}^{-1}$, respectively. ${ }^{[27-29]}$ By comparing these values with the data of Tables 1-3, it can be seen that calculated rotational barriers in the gasphase for these molecules differ only by $0.23-1.18 \mathrm{kcal} \mathrm{mol}^{-1}$ from the experimental values. The calculated rotational barrier for benzaldehyde in this work $\left(8.58 \mathrm{kcal} \mathrm{mol}^{-1}\right)$ is well within the range of calculated values using other theoretical methods $\left(8.282-8.810 \mathrm{kcal} \mathrm{mol}^{-1}\right) \cdot{ }^{[30]}$

An observation of Figure 1 reveals that the changes in $\mathrm{C} 1-\mathrm{C} 2$ and $\mathrm{C} 1=\mathrm{O}$ bond distances between the minimum and transition states correlate very good with the RB between these two states. Further evidence for the shortening of $\mathrm{C} 1=\mathrm{O}$ bond distances comes from the decrease in carbonyl stretching frequencies. Figure SI1 shows that there is a linear relationship between the change in $\mathrm{C} 1=0$ stretching frequency between the minimum and transition states and RB and this is mainly due to decrease in frequency of the minimum states. The $R^{2}$ values in Figure 2 increase from 0.921 to 0.965 if the substituents $\mathrm{O}^{-}$and $\mathrm{OCH}_{2} \mathrm{O}^{-}$are excluded. The experimental carbonyl stretching frequencies are more than $100 \mathrm{~cm}^{-1}$ smaller than the calculated frequencies in this work but the direction of frequency shifts is similar in both. ${ }^{[31,32]}$ It should be noted that the experimental values of carbonyl stretching frequencies vary with solvents and affected by intermolecular hydrogen bonding and relative basicity of $\mathrm{C}=\mathrm{O}$ group. ${ }^{[32]}$ 
The changes in natural atomic charges for the carbonyl carbon and oxygen between the transition and minimum states correlate very well with RB, as shown in Figure 2. The natural atomic charge has been reported to be reliable for similar systems and superior to other forms of charges. ${ }^{[33,34]}$ The correlation of change in minimum electrostatic potential with RB is presented quantitatively in Figure SI2. The relatively lower linear correlation coefficient

Table 4. Calculated rotational barrier and differences of parameters between minimum (Table 1) and transition (Table 2) states of para-substituted benzaldehydes.

\begin{tabular}{|c|c|c|c|c|c|c|c|}
\hline Substituent $X$ & $\mathrm{RB} / \mathrm{kcal} \mathrm{mol}^{-1}$ & $\Delta R(\mathrm{C} 1-\mathrm{C} 2) / \AA$ & $\Delta R(\mathrm{C} 1=\mathrm{O}) / \AA$ & $V_{\mathrm{C} 1=\mathrm{o}} / \mathrm{cm}^{-1}$ & $\Delta Q_{n}(\mathrm{C} 1) / \mathrm{e}$ & $\Delta Q_{\mathrm{n}}(\mathrm{O}) / \mathrm{e}$ & $\Delta E S_{\min } / \mathrm{kJ} \mathrm{mol}^{-1}$ \\
\hline $\mathrm{O}^{-}$ & 19.28 & 0.050 & -0.016 & 50 & 0.078 & 0.086 & \\
\hline $\mathrm{OCH}_{2} \mathrm{O}^{-}$ & 17.76 & 0.048 & -0.014 & 52 & 0.068 & 0.080 & \\
\hline $\mathrm{S}^{-}$ & 15.08 & 0.042 & -0.012 & 49 & 0.057 & 0.068 & \\
\hline $\mathrm{NNO}_{2}^{-}$ & 13.92 & 0.040 & -0.010 & 44 & 0.048 & 0.061 & \\
\hline $\mathrm{O}\left(\mathrm{CH}_{2}\right)_{2} \mathrm{O}^{-}$ & 12.65 & 0.035 & -0.008 & 38 & 0.038 & 0.054 & \\
\hline $\mathrm{OPO}_{3} \mathrm{H}^{-}$ & 12.01 & 0.034 & -0.007 & 32 & 0.034 & 0.049 & \\
\hline $\mathrm{CH}_{2} \mathrm{CO}_{2}^{-}$ & 11.69 & 0.031 & -0.008 & 33 & 0.032 & 0.048 & \\
\hline $\mathrm{NHCH}_{3}$ & 11.12 & 0.031 & -0.006 & 25 & 0.021 & 0.045 & 16.03 \\
\hline $\mathrm{N}\left(\mathrm{C}_{2} \mathrm{H}_{5}\right)_{2}$ & 11.04 & 0.032 & -0.006 & 25 & 0.023 & 0.045 & 17.24 \\
\hline $\mathrm{CO}_{2}^{-}$ & 10.87 & 0.029 & -0.006 & 28 & 0.031 & 0.040 & \\
\hline $\mathrm{NH}_{2}$ & 10.62 & 0.030 & -0.005 & 23 & 0.020 & 0.043 & 14.10 \\
\hline $\mathrm{N}\left(\mathrm{CH}_{3}\right)_{2}$ & 10.52 & 0.031 & -0.006 & 22 & 0.021 & 0.044 & 17.99 \\
\hline $\mathrm{O}\left(\mathrm{CH}_{2}\right)_{2} \mathrm{CH}_{3}$ & 10.15 & 0.027 & -0.005 & 19 & 0.017 & 0.037 & 13.74 \\
\hline $\mathrm{OH}$ & 9.98 & 0.027 & -0.005 & 18 & 0.015 & 0.039 & 11.88 \\
\hline $\mathrm{OCH}_{3}$ & 9.87 & 0.027 & -0.005 & 21 & 0.016 & 0.038 & 12.11 \\
\hline $\mathrm{OCH}_{2} \mathrm{CH}_{3}$ & 9.78 & 0.027 & -0.005 & 21 & 0.016 & 0.038 & 12.06 \\
\hline $\mathrm{OC}_{6} \mathrm{H}_{5}$ & 9.68 & 0.027 & -0.005 & 19 & 0.015 & 0.037 & 11.61 \\
\hline $\mathrm{OCH}\left(\mathrm{CH}_{3}\right)_{2}$ & 9.63 & 0.028 & -0.005 & 20 & 0.017 & 0.038 & 13.14 \\
\hline $\mathrm{N}=\mathrm{NN}\left(\mathrm{CH}_{3}\right)_{2}$ & 9.44 & 0.025 & -0.005 & 19 & 0.015 & 0.035 & 10.45 \\
\hline $\mathrm{F}$ & 9.21 & 0.024 & -0.005 & 15 & 0.011 & 0.033 & 10.77 \\
\hline SH & 9.20 & 0.024 & -0.004 & 16 & 0.012 & 0.033 & 11.59 \\
\hline $\mathrm{SCH}_{3}$ & 9.20 & 0.025 & -0.005 & 20 & 0.014 & 0.034 & 11.10 \\
\hline 2-furyl & 9.10 & 0.024 & -0.004 & 16 & 0.014 & 0.033 & 11.00 \\
\hline $\mathrm{CH}_{2} \mathrm{CH}_{3}$ & 9.08 & 0.023 & -0.004 & 17 & 0.013 & 0.031 & 8.26 \\
\hline $\mathrm{C}_{5} \mathrm{H}_{10}$ & 9.05 & 0.023 & -0.004 & 16 & 0.013 & 0.031 & 9.01 \\
\hline $\mathrm{CH}_{3}$ & 9.01 & 0.023 & -0.004 & 15 & 0.013 & 0.031 & 8.37 \\
\hline$\left(\mathrm{CH}_{2}\right)_{2} \mathrm{CH}_{3}$ & 8.99 & 0.023 & -0.004 & 15 & 0.013 & 0.031 & 8.39 \\
\hline $\mathrm{CH}\left(\mathrm{CH}_{3}\right)_{2}$ & 8.97 & 0.023 & -0.004 & 17 & 0.013 & 0.031 & 9.54 \\
\hline $\mathrm{C}\left(\mathrm{CH}_{3}\right)_{3}$ & 8.94 & 0.023 & -0.004 & 14 & 0.013 & 0.031 & 9.62 \\
\hline $\mathrm{C}_{6} \mathrm{H}_{5}$ & 8.83 & 0.023 & -0.004 & 15 & 0.012 & 0.030 & 8.83 \\
\hline $\mathrm{CH}=\mathrm{CH}_{2}$ & 8.82 & 0.023 & -0.004 & 16 & 0.013 & 0.030 & 8.85 \\
\hline $\mathrm{CH}_{2} \mathrm{OH}$ & 8.74 & 0.022 & -0.004 & 16 & 0.012 & 0.031 & 7.19 \\
\hline $\mathrm{SiH}\left(\mathrm{CH}_{3}\right)_{2}$ & 8.63 & 0.021 & -0.004 & 15 & 0.011 & 0.028 & 8.29 \\
\hline $\mathrm{H}$ & 8.58 & 0.022 & -0.003 & 15 & 0.011 & 0.029 & 6.85 \\
\hline $\mathrm{CN}$ & 8.07 & 0.019 & -0.003 & 11 & 0.007 & 0.025 & \\
\hline $\mathrm{NO}_{2}$ & 7.87 & 0.018 & -0.003 & 9 & 0.006 & 0.024 & \\
\hline
\end{tabular}




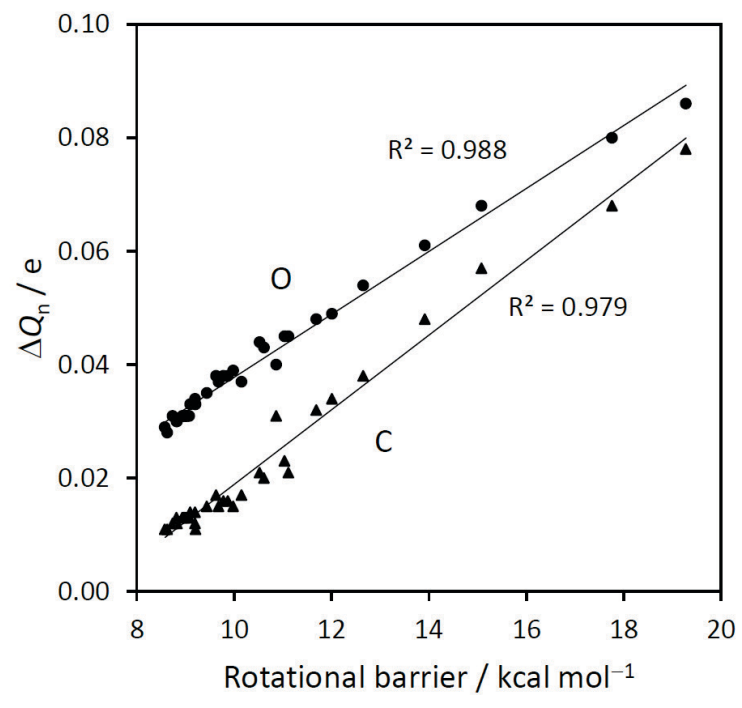

Figure 2. Plot of changes of natural charge on carbonyl oxygen and carbon between minimum and transition states versus rotational barrier of para-substituted benzaldehydes.

(0.870) in Figure SI2 can be attributed to the fact that electrostatic potential is calculated in the vicinity of the two lone pairs on carbonyl oxygen and not at a specific position. As mentioned above, anionic species were not included in this figure.

Figure 3 exhibits excellent linear relationship between change of chemical shifts of formyl carbon NMR spectra between minimum and transition states and RB. The differences between the two states is mainly due to increase in upfield shift in the minimum states. The polarization of the formyl C-H bond due to electrophilic nature of the carbonyl group is reduced by electron-donating substituents and this contributes to high shielding around formyl proton compared to unsubstituted benzaldehyde. Similarly, the polarization of the carbonyl carbon is also expected to be reduced by electron-donating groups and as a result, the peak of carbonyl group appears towards lower field. It was shown experimentally for a few electrondonating substituents at para-position of benzaldehydes that formyl protons and carbon are more shielded in conju gated systems, and the order of lowering in chemical sifts ${ }^{[35-37]}$ follows the trend calculated here. The calculated RBs using EDF2/6-31G* level of theory (Table 3) are larger than those calculated using $\omega B$ 97X-D/6-31G** method (Tables 1, 2, and 4) by less than $2 \mathrm{kcal} \mathrm{mol}^{-1}$. Nevertheless, the order of substituents does not differ significantly between the two methods.

Table 5 shows the calculated values of RBs, stabilization energy, and the Hammett $\sigma_{\mathrm{p}}{ }^{+}$constants for para-substituted benzaldehydes. The stabilization energy correlates well with the RB as shown in Figure SI3. The stabilization

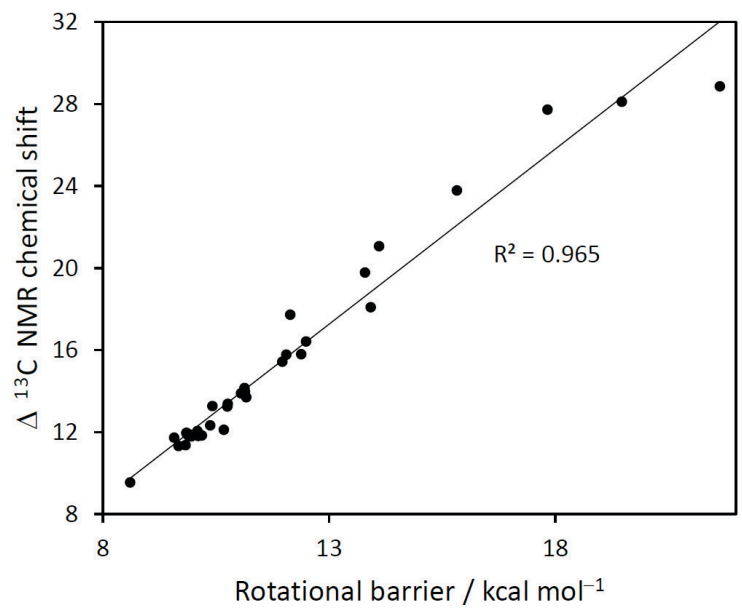

Figure 3. Plot of changes of formyl ${ }^{13} \mathrm{C}$ NMR chemical shifts between minimum and transition states versus rotational barrier of para-substituted benzaldehydes.

energy is the energetic measure of the increase in the stability of a system due to interactions between the substituents. ${ }^{[10,21]}$ An observation of Table 5 reveals that anionic substituents are remarkably more stabilized in comparison to other substituents indicating excellent interaction between these substituents and formyl group across the phenyl ring.

Correlation exists between Hammett $\sigma_{\mathrm{p}}{ }^{+}$constants and RB as shown in Figure 4. Available Hammett constants for the anionic substituents in this study were not included in Figure 4 as they were notably outliers. It is a question in literature for including Hammett constants for charged and neutral substituents in the same scale. ${ }^{[31,37]}$

It can be observed from Table 4 that $\mathrm{CN}$ and $\mathrm{NO}_{2}$ exhibit the lowest change in parameters between the minimum and transition states. They also have negative stabilization energy (Table 5) owing to their electron-accepting property.

\section{Rotational Barrier as a Measure of Substituent Effect}

The shortening of the phenyl carbonyl bond and lengthening of carbonyl bond reveal the electronwithdrawing nature of the formyl group. The shift of electron density towards formyl group was manifested by increase in negative charge on carbonyl carbon and oxygen, as well as by the lowering of NMR chemical shifts of formyl carbon. The changes of all these parameters between minimum and transition states of para-substituted benzaldehydes were found to be highly correlated with rotational barriers between these states. The stronger the electron donor at para-position causes greater change in these parameters and consequently a higher value of rotational barrier is obtained. The structural changes also suggest an increase 


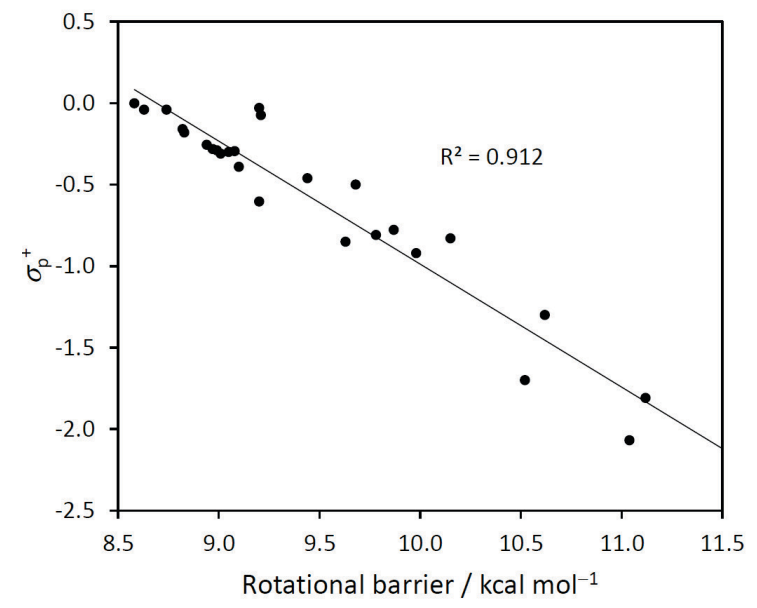

Figure 4. Plot of Hammett $\sigma_{\mathrm{p}}{ }^{+}$constants versus rotational barrier of para-substituted benzaldehydes.

in resonance stabilization with RB and therefore, with the strength of electron donating power of the substituent. Moreover, the stabilization energy and empirical Hammett $\sigma_{\mathrm{p}}{ }^{+}$constants were also found to correlate well with RB.

The bond between atom of $X$ attached to benzene carbon ( $C 5-X$ distance) was found shorter in para-substituted benzaldehydes as compared to that in the absence of aldehyde group. Moreover, the difference between these two distances in the minimum states increases with RB, ranging from almost 0 to $0.023 \AA$. On the other hand, as stated above, the $\mathrm{C} 1-\mathrm{C} 2$ bond distances in para-substituted benzaldehydes are shorter than those in benzaldehydes, ranging from almost 0 to $0.047 \AA$. The $\mathrm{C} 1=\mathrm{O}$ bond distances in para-substituted benzaldehydes are longer than those in benzaldehydes, ranging from almost 0 to $0.02 \AA$. This implies that simultaneous presence of benzaldehyde, a typical electronwithdrawing group, and electron-donating groups at para-position causes more resonance stabilization as compared to the presence of either one of them.

It can be concluded from Tables 3 and 4 that the most prominent changes in parameters occur with anionic substituents because of the direct resonance interaction of the negative charge with the phenyl ring. ${ }^{[11,38]}$ These are followed roughly by electron donors with nitrogen, oxygen, or sulfur atoms bonded to phenyl group at para-position, in that order of decreasing electron donating power. Anionic substituents and substituents with nitrogen, oxygen, or sulfur bonded to phenyl ring result in resonance stabilization through the interaction of their lone pairs with pi electrons of the phenyl ring. This is evidenced by increase of double bond character of the substituent-phenyl and phenylformyl bonds with increasing RB. As a result, more electron delocalization is expected in such systems with larger values of RB. The weakest electron donors are the alkyl groups

Table 5. Calculated rotational barrier, stabilization energy, and Hammett $\sigma_{\mathrm{p}}{ }^{+}$constant of parasubstituted benzaldehydes.

\begin{tabular}{|c|c|c|c|c|c|c|c|}
\hline Substituent X & $\mathrm{RB} / \mathrm{kcal} \mathrm{mol}^{-1}$ & $\mathrm{SE} / \mathrm{kcal} \mathrm{mol}^{-1}$ & $\sigma_{p}^{+}$ & Substituent X & $\mathrm{RB} / \mathrm{kcal} \mathrm{mol}^{-1}$ & $\mathrm{RB} / \mathrm{kcal} \mathrm{mol}^{-1}$ & $\mathrm{RB} / \mathrm{kcal} \mathrm{mol}^{-1}$ \\
\hline $\mathrm{O}^{-}$ & 19.28 & 20.00 & -2.3 & $\mathrm{~N}=\mathrm{NN}\left(\mathrm{CH}_{3}\right)_{2}$ & 9.44 & 1.17 & -0.46 \\
\hline $\mathrm{OCH}_{2} \mathrm{O}^{-}$ & 17.76 & 16.75 & -0.68 & $\mathrm{~F}$ & 9.21 & 0.11 & -0.073 \\
\hline $\mathrm{S}^{-}$ & 15.08 & 13.23 & -2.62 & SH & 9.20 & 0.75 & -0.03 \\
\hline $\mathrm{NNO}_{2}^{-}$ & 13.92 & 11.01 & & $\mathrm{SCH}_{3}$ & 9.20 & 0.70 & -0.604 \\
\hline $\mathrm{O}\left(\mathrm{CH}_{2}\right)_{2} \mathrm{O}^{-}$ & 12.65 & 9.30 & & 2-furyl & 9.10 & 0.44 & -0.39 \\
\hline $\mathrm{OPO}_{3} \mathrm{H}^{-}$ & 12.01 & 7.48 & & $\mathrm{CH}_{2} \mathrm{CH}_{3}$ & 9.08 & 0.55 & -0.295 \\
\hline $\mathrm{CH}_{2} \mathrm{CO}_{2}^{-}$ & 11.69 & 7.30 & -0.53 & $\mathrm{C}_{5} \mathrm{H}_{10}$ & 9.05 & 0.68 & -0.3 \\
\hline $\mathrm{NHCH}_{3}$ & 11.12 & 2.83 & -1.81 & $\mathrm{CH}_{3}$ & 9.01 & 0.58 & -0.311 \\
\hline $\mathrm{N}\left(\mathrm{C}_{2} \mathrm{H}_{5}\right)_{2}$ & 11.04 & 3.23 & -2.07 & $\left(\mathrm{CH}_{2}\right)_{2} \mathrm{CH}_{3}$ & 8.99 & 0.53 & -0.29 \\
\hline $\mathrm{CO}_{2}^{-}$ & 10.87 & 7.17 & -0.02 & $\mathrm{CH}\left(\mathrm{CH}_{3}\right)_{2}$ & 8.97 & 0.58 & -0.28 \\
\hline $\mathrm{NH}_{2}$ & 10.62 & 2.49 & -1.3 & $\mathrm{C}\left(\mathrm{CH}_{3}\right)_{3}$ & 8.94 & 0.64 & -0.256 \\
\hline $\mathrm{N}\left(\mathrm{CH}_{3}\right)_{2}$ & 10.52 & 3.00 & -1.7 & $\mathrm{C}_{6} \mathrm{H}_{5}$ & 8.83 & 0.21 & -0.179 \\
\hline $\mathrm{O}\left(\mathrm{CH}_{2}\right)_{2} \mathrm{CH}_{3}$ & 10.15 & 1.56 & -0.83 & $\mathrm{CH}=\mathrm{CH}_{2}$ & 8.82 & 0.17 & -0.16 \\
\hline $\mathrm{OH}$ & 9.98 & 1.44 & -0.92 & $\mathrm{CH}_{2} \mathrm{OH}$ & 8.74 & 0.17 & -0.04 \\
\hline $\mathrm{OCH}_{3}$ & 9.87 & 1.14 & -0.778 & $\mathrm{SiH}\left(\mathrm{CH}_{3}\right)_{2}$ & 8.63 & -0.02 & -0.04 \\
\hline $\mathrm{OCH}_{2} \mathrm{CH}_{3}$ & 9.78 & 1.61 & -0.81 & $\mathrm{H}$ & 8.58 & 0.00 & 0 \\
\hline $\mathrm{OC}_{6} \mathrm{H}_{5}$ & 9.68 & 0.93 & -0.5 & $\mathrm{CN}$ & 8.07 & -1.85 & 0.66 \\
\hline $\mathrm{OCH}\left(\mathrm{CH}_{3}\right)_{2}$ & 9.63 & 1.65 & -0.85 & $\mathrm{NO}_{2}$ & 7.87 & -2.32 & 0.79 \\
\hline
\end{tabular}


and the $\mathrm{SiH}\left(\mathrm{CH}_{3}\right)_{2}$ substituent which have rotational barriers very close to that of benzaldehyde. The alky groups are electron donors by inductive effect which is notably less significant than the resonance effect in compounds studied here. Although fluorine has a slightly higher RB than alkyl groups, the change in parameters in presence of fluorine is comparable to those associated with alkyl groups and even with benzaldehyde like $\mathrm{SE}, v_{\mathrm{C} 1=0}, \Delta Q_{\mathrm{n}}(\mathrm{C} 1)$, and $\sigma_{\mathrm{p}}{ }^{+}$. Therefore, $\mathrm{F}$ is a weak electron donor although some resonance effect is still possible due to richness of lone pairs.

The central $\mathrm{C}-\mathrm{C}$ bond distances ( $\mathrm{C} 3-\mathrm{C} 4$ and $\mathrm{C} 6-\mathrm{C} 7$ ) of benzene in para-substituted benzaldehydes were found shorter than the lateral $\mathrm{C}-\mathrm{C}$ bond distances, and the difference between the two increases with RB.

Based on above discussion, one can visualize a canonical-like structure (Scheme 2(b)) to be dominant in case of strong electron-donating substituents with lone pair(s) on the atom bonded to the phenyl ring at para-position. Groups with low RB are presumed to have structures similar to that in Scheme 2(a) which is much similar to benzaldehyde. Lower values of $\mathrm{RB}$ for $\mathrm{CN}$ and $\mathrm{NO}_{2}$ indicate lower double bond character of the $\mathrm{C} 1-\mathrm{C} 2$ bond and thus an insignificant delocalization occurs throughout the whole molecules containing these substituents at para-position of benzaldehyde.

The fact that atomic, geometric, molecular, spectroscopic, and empirical parameters show excellent correlation with RB implies that RB is a good measure of electrondonating substituent effect and resonance stabilization in para-substituted benzaldehydes. Therefore, a quantitative scale for the ability of electron-donating groups to stabilize benzaldehyde can be constructed in terms of RB. Rotational barrier can be considered an alternate quantum mechanical approach to the Hammett constants for quantification of substituent effect. Actually, despite the wide use of Hammett constants, they are not available for new substituents and not very successful for uncommon substituents. ${ }^{[39]}$ Besides, several modifications and corrections of these constants have been reported in literature. ${ }^{[25,40]}$

RB was shown before to be a reliable method to measure $\pi$-conjugation in para-substituted anilines ${ }^{[14]}$ and in disubstituted 1,3-butadienes. ${ }^{[20]}$ These studies include a large number of different substituents and rely on many

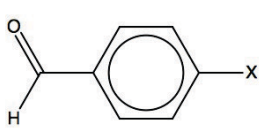

(a)
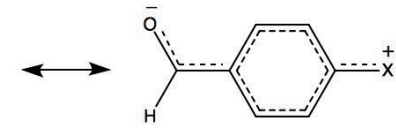

(b)
Scheme 2. Resonance forms of benzaldehyde with conjugated para electron-donating substituent $X$. calculated and empirical parameters that are affected by change of substituents. Moreover, the compatibility between experimental and theoretical values and trends has been achieved with several parameters. Thus, RB is a useful parameter that demonstrates the electron-withdrawing and-donating properties of the aromatic ring substituents at para-positions.

\section{CONCLUSION}

The $\omega B$ 97X-D/6-31G** and EDF2/6-31G* calculations show that the rotational barrier between the transition and $\mathrm{min}$ imum states of para-substituted benzaldehydes with electron-donating groups is a reliable quantum mechanical measure of electron-donating substituent effect and $\pi$-conjugation in these compounds. The extent of conjugation is verified by several structural, atomic, molecular, spectroscopic, and empirical parameters which are shown to be sensitive to substituents and correlate very well with the RB. Hence, based on RB, a quantitative scale for the strength of electron-donating substituents and their ability to resonate with benzaldehyde can be established.

Supplementary Information. Supporting information to the paper is attached to the electronic version of the article at: https://doi.org/10.5562/cca3672.

PDF files with attached documents are best viewed with Adobe Acrobat Reader which is free and can be downloaded from Adobe's web site.

\section{REFERENCES}

[1] T. M. Krygowski, B.T. Stępień, Chem. Rev. 2005, 105, 3482-3512. https://doi.org/10.1021/cr030081s

[2] O. Exner O, S. Böhm, Curr. Org. Chem. 2006, 10, 763778. https://doi.org/10.1021/cr030081s

[3] T. Stuyver, T. Zeng, Y. Tsuji, S. Fias, P. Geerlings, F. De Proft, J. Phys. Chem. C 2018, 122, 3194-3200.

https://doi.org/10.1021/acs.jpcc.7b10877

[4] M. Dudek, Z. Pokładek, M. Deiana, K. Matczyszyn, Dyes Pigm. 2020, 180, 108501.

https://doi.org/10.1016/j.dyepig.2020.108501

[5] R. Iwai, M. Morimoto, M. Irie, Photochem. Photobiol. Sci. 2020,19, 783-789.

https://doi.org/10.1039/DOPP00064G

[6] T. Al-Faouri, F. L. Buguis, S. A. Soldouz, O. V. Sarycheva, B. A. Hussein, R. Mahmood, B. D. Koivisto, Molecules 2020, 25, 2260.

https://doi.org/10.3390/molecules25092260

[7] F. Tian, T. Wang, W. Dang, J. Xiao, X. Zhao, Dyes Pigm. 2020, 177, 108298.

https://doi.org/10.1016/j.dyepig.2020.108298

[8] L. P. Hammett, J. Am. Chem. Soc. 1937, 59, 96-103. https://doi.org/10.1021/ja01280a022 
[9] P. J. Krueger, Can. J. Chem. 1962, 40, 2300-2316. https://doi.org/10.1139/v62-354

[10] H. Szatylowicz, A. Jezuita, T. Siodła, K. S. Varaksin, M. A. Domanski, K. Ejsmont, T. M. Krygowski, ACS Omega 2017, 2, 7163-7171. https://doi.org/10.1021/acsomega.7b01043.

[11] K. S. Varaksin, H. Szatylowicz, T. M. Krygowski, J. Mol. Struct. 2017, 1137, 581-588.

https://doi.org/10.1016/j.molstruc.2017.02.074

[12] I. Israel, G. Frenking, J. Org. Chem. 2006, 71, 22512256. https://doi.org/10.1021/jo052012e

[13] G. S. Remya, C. H. Suresh, Phys. Chem. Chem. Phys. 2016, 18, 20615-20626. https://doi.org/10.1039/C6CP02936A

[14] A. H. Yateem, Mediterr. J. Chem. 2020, 10, 319-334. https://doi.org/10.13171/mjc02004161378ahy

[15] L. Radom, W. J. Hehre, J. A. Pople, G. L. Carlson, W. G. Fateley, J. Chem. Soc., Chem. Commun. 1972, 6, 308-309. https://doi.org/10.1039/C39720000308

[16] A. Halouia, E. Haloui, J. Phys. Org. Chem. 2014, 27, 430-439. https://doi.org/10.1002/poc.3280

[17] T. Drakenberg, J. Sommer, R. Jost, J. Chem. Soc., Perkin Trans. 1980, 2, 363-369. https://doi.org/10.1039/P29800000363

[18] A. Haloui, Y. Arfaoui, J. Mol. Struct.-THEOCHEM 2010, 950, 13-19.

https://doi.org/10.1016/j.theochem.2010.03.012

[19] Z. Li, T. Bally, K. N. Houk, W. T. Borden, J. Org. Chem. 2016, 81, 9576-9584. https://doi.org/10.1021/acs.joc.6b01530

[20] A. H. Yateem, Indones. J. Chem. 2019, 19, 10551065. https://doi.org/10.22146/ijc. 42850

[21] H. Szatylowicz, T. Siodla, O. A. Stasyuk, T. M. Krygowski, Phys. Chem. Chem. Phys. 2016, 18, 11711-11721. https://doi.org/10.1039/C5CР06702B

[22] J.-D. Chai, M. H.-Gordon. Phys. Chem. Chem. Phys. 2008, 10, 6615-6620.

https://doi.org/10.1039/B810189B

[23] SPARTAN'14. Irvine, CA, USA: Wavefunction, 2014.

[24] C. Y. Lin, M. W. George, P. M. W. Gill, Aust. J. Chem. 2004, 57, 365-370. https://doi.org/10.1071/CH03263
[25] C. Hansch, A. Leo, R. W. Taft, Chem. Rev. 1991, 91, 165-195. https://doi.org/10.1021/cr00002a004

[26] H. C. Brown, Y. Okamoto, J. Am. Chem. Soc. 1958, 80, 4979-4987. https://doi.org/10.1021/ja01551a055

[27] J. Seita, S. J. Formosinho, Tetrahedron. 1988, 44, 1707-1710. https://doi.org/10.1016/S0040-4020(01)86734-X

[28] M. A. Leiva, R. G. Morales, V. Vargas, J. Phys. Org. Chem. 1996, 9, 455-458.

https://doi.org/10.1002/(SICI)10991395(199607)9:7<455::AID-POC804>3.0.CO;2-H

[29] F. A. L. Anet, M. Ahmad, J. Am. Chem. Soc. 1964, 86, 119-120. https://doi.org/10.1021/ja01055a031

[30] I. A. Godunov, V. A. Bataev, A. V. Abramenkov, V. I. Pupyshev, J. Phys. Chem. A 2014, 118, 10159-10165. https://doi.org/10.1021/jp509602s

[31] E. A. Velcheva, I. N. Juchnovski, I. G. Binev, Spectrochim. Acta A Mol. Biomol. Spectrosc. 2003, 59, 1745-1749. https://doi.org/10.1016/S1386-1425(02)00398-0

[32] R. A. Nyquist, Appl. Spectrosc. 1992, 46, 306-316

[33] K. C. Gross, P. G. Seybold, Z. P.-Inga, J. S. Murray, P. Politzer, J. Org. Chem. 2001, 66, 69196925. https://doi.org/10.1021/jo010234g

[34] K. Neuvonen, F. Fulop, H. Neuvonen, A. Koch, E. Kleinpeter, K. Pihlaja, J. Org. Chem. 2003, 68, 21512160. https://doi.org/10.1021/jo020608|

[35] S. P.-Elenbaum, J. T. Stanley, D. K. Dillner, S. Lin, D. Traficante, Magn. Reson. Chem. 2006, 44, 797-806. https://doi.org/10.1002/mrc.1851

[36] R. E. Klinck, J. B. Stothers, Can. J. Chem. 1962, 40, 1071-1081. https://doi.org/10.1139/v62-165

[37] S. Marriott, W. F. Reynolds, R. D. Topsom, J. Org. Chem. 1985, 50, 741-743.

https://doi.org/10.1021/jo00206a002

[38] P. J. Vassileva, I. G. Binev, I. N. Juchnovski, Spectrochim. Acta A Mol. Biomol. Spectrosc. 1983, 39, 709-712. https://doi.org/10.1016/0584-8539(83)80116-0

[39] P. Ertl, Quantitative Structure_Activity Relationships. 1997, 16, 377-382. https://doi.org/10.1002/qsar.19970160505

[40] H. H. Jaffé, Chem. Rev. 1953, 53, 191-261. https://doi.org/10.1021/cr60165a003 